OPEN ACCESS

Edited by:

Kerryn Brent,

University of Adelaide, Australia

Reviewed by:

Emily Margaret Cox,

Cardiff University, United Kingdom

Jesse L. Reynolds,

University of California, Los Angeles,

United States

${ }^{*}$ Correspondence:

Christine Merk

christine.merk@ifw-kiel.de

Specialty section:

This article was submitted to Negative Emission Technologies,

a section of the journal

Frontiers in Climate

Received: 12 August 2020 Accepted: 30 November 2020 Published: 21 December 2020

Citation:

Bertram C and Merk C (2020) Public Perceptions of Ocean-Based Carbon

Dioxide Removal: The Nature-Engineering Divide?

Front. Clim. 2:594194.

doi: 10.3389/fclim.2020.594194

\section{Public Perceptions of Ocean-Based Carbon Dioxide Removal: The Nature-Engineering Divide?}

\author{
Christine Bertram and Christine Merk* \\ Research Center Global Commons and Climate Policy, Kiel Insitute for the World Economy, Kiel, Germany
}

Public acceptability is a standard element on the list of potential constraints on research and deployment of ocean-based carbon dioxide removal (CDR). We outline past work on the public perceptions and acceptability of ocean-based CDR among laypersons covering the main developments over the past 15 years. We compare and synthesize insights from two distinct strands of literature - one on climate engineering approaches and the other on coastal ecosystem management or blue carbon approaches. We also draw conclusions from studies on land-based CDR for emerging ocean-based approaches. Main determinants of perceptions identified in the past are controllability, environmental impacts, containment, permanence of carbon storage, risks and benefits for the local population as well as to which degree an approach is perceived as natural or engineered. We highlight how these aspects may influence perceptions and acceptability of ocean-based CDR approaches which have not yet been on the agenda of perceptions research. Even though ocean-based CDR approaches cannot be neatly divided into categories, the public's tendency to favor approaches perceived more as natural over approaches perceived more as engineering could result in a dilemma between approaches with possibly high carbon sequestration potential but low levels of acceptability and approaches with possibly low sequestration potential but high levels of acceptability. To effectively work toward achieving net-zero carbon emissions by midcentury, however, we need to bridge the gap between natural and engineering-type approaches, also in research, to come up with a broad portfolio of CDR options to complement classic mitigation and adaptation measures.

Keywords: public perception, ocean-based carbon dioxide removal (CDR), climate engineering, nature-based solution, blue carbon, acceptance, negative emission technology, naturalness

\section{INTRODUCTION}

Intentionally removing carbon dioxide from the atmosphere will be important to achieve net-zero emissions by mid-century and to limit global warming to $1.5^{\circ} \mathrm{C}$ by 2100 . However, the climate change mitigation pathways that include negative emissions via carbon dioxide removal (CDR) are still largely restricted to the land-based approaches afforestation and bioenergy with carbon capture and storage (IPCC, 2018). Relying on the large-scale deployment of these approaches, for example as monoculture plantations, would exacerbate land-use competition, nitrogen pollution, and biodiversity loss (Smith et al., 2019). Portfolios of many different approaches would thus 
increase the feasibility and sustainability of CDR as trade-offs and side-effects vary between methods and scale matters (IPCC, 2018; Smith et al., 2019). As the ocean is the largest natural carbon sink, ideas to (artificially) enhance carbon uptake and storage via ocean iron fertilization or direct injection of $\mathrm{CO}_{2}$ into the deep ocean have already been discussed in the 1990s and early 2000s (GESAMP, 2019). These approaches have often been categorized as geoengineering or climate engineering. More recently, the potential of blue carbon or coastal ecosystem management, i.e., the conservation and restoration of mangroves, salt marshes and seagrass meadows, for carbon sequestration and thus for combating climate change has been put on the political as well the research agenda (Hoegh-Guldberg et al., 2019a,b). These approaches are often categorized as nature-based solutions.

Public acceptability ranks highly on the list of potential constraints on CDR deployment (Fuss et al., 2014; IPCC, 2018; GESAMP, 2019; Rickels et al., 2019). In an expert survey, earth system modelers and integrated assessment modelers perceived political and public acceptability on average as the strongest constraint on the feasibility of ocean iron fertilization, alkalinity enhancement, and artificial upwelling followed by cost effectiveness. In contrast, they only saw it as a weak constraint on blue carbon management (Rickels et al., 2019). This assessment of the role of public acceptability might partly be fueled by past protests against research projects such as LOHAFEX on ocean iron fertilization in the Southern Ocean (Schiermeier, 2009a,b) and SPICE on stratospheric aerosol injection in the UK (Pidgeon et al., 2013), proposals for $\mathrm{CO}_{2}$-injection off the coast of Hawaii and Norway (Gewin, 2002; Giles, 2002; Figueiredo et al., 2003; Scott, 2006) or the ocean fertilization project by the Haida Salmon Restoration Corporation in international waters off the Canadian west coast (Tollefson, 2017; Gannon and Hulme, 2018).

Our perspective summarizes the research on the perceptions and acceptability of ocean-based CDR options among laypersons covering the main developments over the past 15 years. We compare and synthesize the insights from two distinct strands of literature - one on approaches often labeled as climate engineering and the other on blue carbon management often labeled as a nature-based solution. The main determinants of acceptability of CDR options we identify are the perception of benefits and risks for the local population, environmental impacts, permanence of carbon storage, controllability, containment and naturalness. We argue that ocean-based approaches that include a release of materials into the ocean are less accepted than land-based approaches as their impact is not contained but can potentially spread out through the ocean constituting a global common. Diverging interests between local and global populations should be addressed by political actors via the installation of trustworthy institutions and well-designed management schemes. There is a rift in the acceptability between approaches that are perceived as natural, i.e., blue carbon management, and approaches that are perceived as climate engineering that is also driven by their perceived naturalness. We argue that this could result in a polarization between ocean-based CDR approaches with high carbon sequestration potential but a low level of acceptability and ocean-based CDR approaches with a low sequestration potential but a high level of acceptability, severely limiting the available options for portfolios of CDR approaches. However, this divide should be bridged to achieve net-zero.

\section{LITERATURE REVIEW}

In this perspective, we focus on public perceptions of oceanbased CDR approaches drawing on studies directly covering specific approaches (e.g., iron fertilization and mangrove conservation and restoration) and comparable approaches for which very few or no specific studies exist yet (e.g., enhanced weathering on land for ocean alkalinization; mangroves for seagrass; see Table 1).

We identify two perspectives on perceptions of ocean-based CDR that are rooted in different interdisciplinary research communities. One perspective is centered on the goal of carbon removal looking at methods like iron fertilization and alkalinity enhancement which tend to be categorized as climate engineering and have mainly been explored in global earth system models (Keller et al., 2018). Perceptions studies in this context have looked at CDR from a global commons perspective in the sense that participants mainly assessed the options based on their impact on global atmospheric $\mathrm{CO}_{2}$-concentrations and environmental impacts on the oceans. Local perspectives of directly affected populations are missing-with the exception of the case study on the Haida Salmon Restoration Project (Gannon and Hulme, 2018) — as it remains very hypothetical who would be directly affected by the deployment of these CDR options.

The other perspective centers on ecosystem services (ES) and local field studies of blue carbon management and has only recently started to incorporate carbon uptake. CDR options such as blue carbon management are categorized as nature-based solutions (Hoegh-Guldberg et al., 2019a). The large body of literature on the perceptions and attitudes toward coastal blue carbon management takes an exclusively local perspective and analyses the perceptions and attitudes of the directly affected local population. The global commons perspective is not present in these studies with the exception of relatively recent ones (e.g., Arumugam et al., 2020).

\section{Public Perceptions of Climate-Engineering Type Approaches}

There are only a few studies on the public perceptions of oceanbased CDR options that come from the climate engineering context, namely a few large-N surveys that include ocean fertilization or alkalinitiy enhancement (Ipsos MORI, 2010; Leiserowitz et al., 2010; Jobin and Siegrist, 2020) and several small-N studies on the perception of direct ocean injection or ocean iron fertilization (Palmgren et al., 2004; Itaoka et al., 2009; Bostrom et al., 2012; Amelung and Funke, 2015; Gannon and Hulme, 2018; Shrum et al., 2020). The approaches that have not yet received a lot of attention in natural science research, such as artificial down- or upwelling, biomass dumping or ocean alkalinity enhancement, have not yet been covered by perceptions research either (see Table 1). 
TABLE 1 | Overview of public perceptions research on ocean-based CDR approaches and other relevant studies.

\section{General description}

Studies on the perceptions of the approach, comparable approaches or components of the approach

Direct injection or dissolution

Ocean fertilization

Ocean alkalinization

Artificial upwelling or downwelling

Direct $\mathrm{CO}_{2}$ removal from seawater with CCS

Terrestrial biomass dumping

Marine biomass for biochar or bioenergy

Blue carbon management
Inject liquid $\mathrm{CO}_{2}$ directly into the mid/deep ocean or the seabed. The dissolved inorganic carbon (DIC) will remain isolated from the atmosphere for centuries or longer depending on ocean circulation/ventilation at the location of injection. ${ }^{b}$
Add micronutrients like iron or macronutrients like nitrogen and phosphorus to increase phytoplankton growth $\left(\mathrm{CO}_{2}\right.$ fixation) and ocean carbon storage via the biological pump (the transport of this fixed carbon into the deep ocean). ${ }^{a}$

Increase the alkalinity of the upper ocean to chemically increase the carbon storage capacity of seawater and thus, also increase $\mathrm{CO}_{2}$ uptake. ${ }^{a}$
Palmgren et al. (2004), Itaoka et al. (2009)

Ipsos MORI (2010), Leiserowitz et al. (2010), Bostrom et al. (2012), Amelung and Funke (2015), Gannon and Hulme (2018), Jobin and Siegrist (2020), Shrum et al. (2020)

Ipsos MORI (2010)

Enhanced weathering on land: Wright et al. (2014), Carlisle et al. (2020), Cox et al. (2020), Shrum et al. (2020)

$-$

Use pipes or other methods to pump nutrient rich deep ocean water to the surface where it has a fertilizing effect (upwelling) ${ }^{a}$; pump down surface waters saturated in $\mathrm{CO}_{2}$ into the ocean interior to enhance the solubility pump of carbon (downwelling). ${ }^{\text {b }}$

Remove DIC from the ocean and transport it to sites for long-term storage as for other CCS-schemes. The subsequent return to equilibrium between the ocean and the atmosphere will involve absorption of $\mathrm{CO}_{2}$ from the atmosphere. $^{\text {b }}$

Sink bales of crop residues in the deep oceans or off the deltas of major rivers. ${ }^{\text {b }}$

Use marine biomass to fuel biomass energy with CCS (BECCS) on land or use such biomass to produce biochar as a soil additive. ${ }^{\mathrm{C}}$

Conserve and restore coastal ecosystems such as mangroves, salt marshes, and seagrass meadows to maintain or enhance carbon storage in biomass and soils. $^{d}$
Only studies on CCS, for a recent overview see Paluszny et al. (2020)

Only studies on Bioenergy with CCS, for a recent overview see Thomas et al. (2018)

No studies on seagrass

Mangroves: e.g., Rönnbäck et al. (2007), Badola et al. (2012), Roy (2016); salt marshes: e.g., Liski et al. (2019) and Curado et al. (2014)

a Description taken from Keller et al. (2018).

b Description based on GESAMP (2019).

c Description based on Gattuso et al. (2018).

d Description based on Hoegh-Guldberg et al. (2019a).

Direct injection of $\mathrm{CO}_{2}$ was evaluated very negatively compared to technologies that lower emissions such as energy from renewable sources or energy efficiency increases (Palmgren et al., 2004). Direct injection and dissolution were also perceived less favorably compared to geological storage, i.e., CCS (Palmgren et al., 2004; Itaoka et al., 2009). Participants in focus groups perceived deep-ocean injection as harmful for the marine environment and its permanence as uncertain, thus, they evaluated it unfavorably (Gough et al., 2002). Respondents with stronger pro-environmental attitudes, such as the perception of nature as being fragile or the rejection of anthropocentrism, perceived deep-ocean injection more negatively (Palmgren et al., 2004).

For ocean fertilization, studies in the US show that $64 \%$ of Americans did not believe or did not know whether it would actually help against climate change (Leiserowitz et al., 2010).
It is perceived more negatively compared to any land-based CDR such as afforestation or direct air capture (Ipsos MORI, 2010; Jobin and Siegrist, 2020). In comparative studies, the perceptions of ocean fertilization are similar to the perceptions of stratospheric aerosol injection: the level of support is low (Ipsos MORI, 2010; Jobin and Siegrist, 2020) and the perceived risks are high (Amelung and Funke, 2015).

In an early study (Bostrom et al., 2012), ocean fertilizationunlike afforestation -was not perceived as a natural solution but as an engineering solution, falling into the same category as stratospheric aerosol injection and nuclear energy. Approaches in the engineering category were favored by respondents that believed more strongly in the controllability of climate change, saw a moral responsibility to fight climate change, and were more likely to believe that climate change was not caused by carbon emissions but by volcanic eruptions (Bostrom et al., 2012). 
Thus, the general finding that CDR options are perceived more positively compared to solar radiation management approaches like stratospheric aerosol injection (Wright et al., 2014; Carlisle et al., 2020) has so far not been confirmed for ocean fertilization and ocean dilution approaches; and it might not hold for ocean alkalinization either.

In the only study on ocean alkalinity enhancement so far, the majority of participants in a public dialogue in the UK were not supportive of the idea (Ipsos MORI, 2010). In focus groups on the perceptions of enhanced weathering on land, participants rejected it especially because of the environmental impacts they perceived downstream for the oceans and related to the necessary large-scale mining (Cox et al., 2020) - both factors also pertain to ocean alkalinization. Comparing further the application of onshore and offshore options, we find only small differences for geological $\mathrm{CO}_{2}$-storage. Studies showed either a small positive effect for offshore storage (Itaoka et al., 2009; Schumann et al., 2014) or no substantial difference (Gough et al., 2002; Upham and Roberts, 2011). There is thus little support for the notion that ocean-based methods might be perceived more positively just because they are farther away. In contrast, the importance of the link between enhanced weathering and the oceans implies that the preservation of the marine environment is a very salient issue.

\section{Local Perceptions of the Restoration and Conservation of Blue Carbon Ecosystems}

There is a large literature on the attitudes and perceptions of local communities and other stakeholders toward mangrove management mostly based on surveys (e.g., Badola et al., 2012), semi-structured interviews (e.g., López-Medellín et al., 2011), and, more recently, the Q-methodology (Hugé et al., 2016; Vande Velde et al., 2019; Arumugam et al., 2020). Also for salt marshes, there is a quite substantial body of literature on attitudes toward conservation and restoration of salt marshes, again mostly using surveys and/or semi-structured interviews with the local public.

In studies on mangroves, the multifaceted interaction between people's dependence on the ecosystem and their attitudes toward and preferences for ecosystem conservation and restoration becomes obvious. Here, we can only sketch the most important interlinkages, for a much deeper discussion of the complex social-ecological interactions surrounding mangrove conversion, conservation, and restoration see e.g., Srivastava and Mehta (2017). Most notably, people value in particular the ES that are directly relevant for sustaining their livelihoods such as the provision of timber, fuelwood, tannin, honey, beeswax, fodder, and thatch (e.g., Roy, 2016). People that rely on nonextractive uses of mangrove forests highly value ES such as storm protection and the provision of nursery habitats and are often more in favor of mangrove conservation and restoration (Stone et al., 2008; López-Medellín et al., 2011; Badola et al., 2012). In contrast, people that rely more on extractive uses would more often object to a total closure for the protection of mangrove forests, a trend which is enforced if potential disservices from mangrove forests are considered (e.g., Badola et al., 2012; Roy, 2016).
Attitudes toward mangrove conservation and restoration also vary with the socio-demographic background of the respondents, i.e., gender (Rönnbäck et al., 2007; Badola et al., 2012), education level, awareness of mangrove loss and provided ES (Badola et al., 2012; Rahman and Asmawi, 2016; Roy, 2016). In this context, a higher level of education seems to be related to a higher awareness of conservation issues (Badola et al., 2012). Moreover, there is some recent evidence that the socio-cultural background also influences attitudes toward mangrove conservation and restoration with urban populations focusing more strongly on recreational ES (Vande Velde et al., 2019). However, differences in perceptions can also be explained by the degree to which a community feels attached and connected to nature, with communities living in close contact to nature highly valuing conservation (Queiroz et al., 2017). Another important factor influencing acceptability of conservation is the way in which management is implemented and benefit sharing schemes are designed (Ha et al., 2012).

For salt marshes, similar but varying factors have been found to influence attitudes and perceptions. For example, possibilities for public access particularly increase the likelihood of accepting restoration or conservation measures. Moreover, socio-demographics influence perceptions with, for example, women and higher-income individuals favoring conservation over restoration (Bauer et al., 2004). Visual aspects such as bright coloring of plants and higher diversity of tones of color but also the reduction of visible garbage positively influence perceptions (Casagrande, 1997; Curado et al., 2014). Similarly, more education about and higher awareness of the ecological functions increase acceptance (Ibrahim et al., 2012), while expected economic losses from proposed policy measures can lead to lower acceptance levels (Liski et al., 2019).

There is, however, much less literature on attitudes and perceptions toward the conservation and restoration of seagrass meadows, and seagrass is often not considered in coastal management decisions (Grech et al., 2012; Nordlund et al., 2014). Nordlund et al. (2018) gathered the impression from expert workshop that the public seems to be mostly unaware of seagrasses in general and the ES they provide in particular. Jefferson et al. (2014) underscore this by finding that the ecologically most valuable species, including three plant species, were considered least interesting in a survey on public perceptions of coastal ecosystems in the UK, reflecting the low appeal of plants compared to animals (Wandersee and Schussler, 2001).

\section{THE IMPLICATIONS OF PUBLIC ACCEPTABILITY FOR THE FEASIBILITY OF OCEAN-BASED CDR APPROACHES}

The two strands of perceptions research on CDR options have so far almost exclusively either taken a global commons perspective for climate-engineering type approaches or a local perspective for blue carbon approaches. Bringing in the missing perspective will 
add further complexity to the issue: the global interest to preserve or expand areas for blue carbon ecosystems to increase carbon uptake or deploy, for example, alkalinity enhancement might clash with the perceptions and needs of the local population that socially and economically depends on the coastal ecosystems. We know that blue carbon management can be attractive for the local population, if the people, directly or indirectly, benefit from the conservation and/or restoration of coastal ecosystems and their basic needs are not threatened. Public opposition to blue carbon approaches could, for example, occur when there are local conflicts around the use of land and resources for mangrove forests and salt marshes (e.g., Myatt et al., 2003; West, 2010). Furthermore, there is no clear case as to whether opposition predominantly comes from local or global actors - such as non-local population, (inter)national NGOs or experts. For example, the development of CCS in Germany faced strong local opposition (Dütschke, 2011). The Haida Salmon Restoration Project evoked polarized views among locals, support from non-locals with business interests and opposition from (inter-)national NGOs and researchers (Gannon and Hulme, 2018).

There is, however, one overarching factor that is indispensable for broad acceptance, both on the local and on the global level: trust in institutions and governance will be crucial for the acceptability of research from the global perspective like it is from the local perspective. Local support can be strengthened if the management regime is well designed and trust in local institutions and the provision of compensations is high (e.g., Stone et al., 2008; Badola et al., 2012; Roy, 2016; Liski et al., 2019). For CCS, it has also been shown that trust in institutions influences perceptions positively (L'Orange Seigo et al., 2014; Braun et al., 2018; Paluszny et al., 2020).

The distinction between local and global is not just a matter of geographic closeness and direct affectedness but also of (perceived) containment and control of environmental impacts. Participants in deliberative workshops listed controllability of climate engineering approaches as an important factor for their assessment (Ipsos MORI, 2010; Pidgeon et al., 2013). Thus, one factor of concern about ocean fertilization in the context of the Haida Salmon Restoration Project was the lack of control when materials are released into the ocean which is perceived as a dynamic and interconnected system. The study participants that loaded high on that factor in the Q-sort acknowledged the need to act against climate change but would have preferred contained climate engineering approaches. Afforestation or direct air capture, where no materials are released into the wider environment, would count as such approaches, while alkalinity enhancement would not (referred to as encapsulation in Royal Society, 2009). For blue carbon approaches, these considerations would imply that the conservation and restoration of coastal ecosystems can be expected to have a high level of acceptability from a global commons perspective as is the case for afforestation on land (Ipsos MORI, 2010; Braun et al., 2018; Jobin and Siegrist, 2020).

The distinction between global and local gets a little more blurred if we widen the scope and look at perceptions of climate engineering options research carried out in non-Western contexts with groups of people that are already experiencing negative impacts of climate change. For example, Gannon and Hulme (2018) reported a sense of urgency to take actions against climate change and threats to the marine environment that mobilized parts of the Haida community to support the ocean fertilization project. At the same time, members of the local First Nations community felt the experiment was a morally wrong intervention into nature and felt powerless against decisions of "global people" (Gannon and Hulme, 2018, p. 12). Similar ambiguity was reported by Carr and Yung (2018) who found that populations vulnerable to climate change would accept climate engineering due to the severe impacts of climate change they are already experiencing. This acceptability, however, was characterized as being "both deeply reluctant and highly conditional." Similar to findings in Winickoff et al. (2015), participants interviewed by Carr and Yung (2018) feared that climate engineering was employed as a quick fix by the Western countries without addressing the real causes of climate change. Strengthening commitments to existing efforts to reduce greenhouse gas emissions by the Western countries was thus one major condition for acceptability. In the context of blue carbon management, the increasing awareness of climate change and the potential of coastal ecosystems to contribute to carbon sequestration could induce even stronger preferences for the conservation of these ecosystems to halt further losses among the local population (Tuan et al., 2014; Arumugam et al., 2020).

In addition to the factors described already, perceived naturalness of CDR options influences acceptability. In particular, labeling CDR options as natural increases acceptability and attaches the meaning of nature as pure, permanent and balanced if left alone, while unnatural bears the connotation of immoral and dangerous (Hansen, 2006). For blue carbon management, local people's attachment and connectedness to nature can be observed to influence perceptions of conservation favorably (Queiroz et al., 2017). For land-based CDR approaches, there is an implicit hierarchy in perceptions where seemingly more natural solutions are prioritized over approaches that are perceived as engineering (Merk et al., 2019). Bio-energy with CCS and enhanced weathering are perceived less favorably compared to biochar or afforestation (Merk et al., 2019; Wolske et al., 2019; Carlisle et al., 2020; Cox et al., 2020). Study participants that perceived approaches as unnatural or as tampering with nature evaluated them more negatively (Corner et al., 2013; Wolske et al., 2019).

However, the categorization of approaches into nature-based solutions and climate engineering seems somewhat arbitrary. Bellamy and Osaka (2020) used ocean alkalinization as an example to show that the concept of nature-based CDR is not a definite characteristic of any method but is rather constructed: the process enhances a natural process in the otherwise (relatively) untouched natural marine environment. What is considered natural depends on time, geography, and culture. Naturalness is thus socially constructed. Corner and Pidgeon (2014) showed that framing direct air capture as artificial trees compared to presenting them in a very technical way resulted in more positive views. Framing something as natural or unnatural can thus be a powerful tool in any public debate 
to steer the desirability of approaches (Demeritt, 2002; Hansen, 2006; Bellamy and Osaka, 2020) even though all options require human action or intervention and are neither fully natural nor unnatural (Bellamy and Osaka, 2020).

\section{WHAT THE FUTURE MIGHT BRING FOR OCEAN-BASED CDR}

It is yet somewhat unclear what the actual carbon removal potential of scaled up deployment of any of the ocean-based CDR options would be. Based on modeling studies (Ilyina et al., 2013; Keller et al., 2014), a recent comprehensive review found that ocean alkalinization applied at the global scale is the CDR method that stands out as having by far the highest potential to increase ocean carbon uptake with practically permanent storage but potentially substantial environmental side-effects (Gattuso et al., 2018). Compared to this theoretically high potential, the sequestration potential of conserving and restoring coastal ecosystems on a global scale is limited even though it would also be permanent if the ecosystems were sufficiently protected. However, Gattuso et al. (2018) rate the carbon sequestration potential of conserving and restoring coastal ecosystems as comparable to that of ocean fertilization carried out at the global scale, but the carbon taken up by the ocean via ocean fertilization would outgas back to the atmosphere over decades to centuries.

The insights from perceptions research presented in this perspective in combination with insights from Gattuso et al. (2018) highlight one important aspect related to the implementation of CDR measures and the goal of reaching net-zero $\mathrm{CO}_{2}$ emissions by mid-century: there is no silver bullet for reaching net-zero by 2050 in the sense that we will probably not be able to find the one measure that has a high carbon sequestration potential, high levels of perceived naturalness and low environmental side effects. While nature-based solutions with potentially higher levels of acceptance can contribute to a portfolio of measures counteracting climate change, other measures with potentially lower acceptance and/or larger detrimental environmental side effects will likely still be needed to reach international climate goals. This in particular holds since ecosystem restoration, particularly for seagrass ecosystems or open ocean ecosystems, is still in its infancy (Franke et al., 2020) even though conservation of coastal ecosystems and restoration of mangroves are well-established practices. Moreover, coastal ecosystems are themselves under threat due to anthropogenic pressures arising e.g., from eutrophication and climate change (Macreadie et al., 2019; Lovelock and Reef, 2020). A deepening polarization between climate engineering approaches and nature-based solutions could lead to "ideologically-motivated

\section{REFERENCES}

Amelung, D., and Funke, J. (2015). Laypeople's risky decisions in the climate change context: climate engineering as a risk-defusing strategy? Hum. Ecol. Risk Asses. Int. J. 21, 533-559. doi: 10.1080/10807039.2014.932203 pushback" (Colvin et al., 2020, p. 28) against certain CDR options independently of actual risks and benefits. An upfront exclusion of many ocean-based approaches would severely hamper the feasibility of balanced CDR portfolios.

Summing up, public perceptions will likely play a big role for the feasibility of research and eventual deployment of oceanbased CDR. Important determinants will be to which degree they are perceived as natural, controllable, permanent, and beneficial both for local communities and not directly affected publics. The challenge for future (perceptions) research will be to specify more precisely who is affected by the deployment of CDR in what ways and to which degree people would actually feel affected. This will be crucial to identify potential constraints on the implementation of CDR options from the global commons perspective and the local perspective on risks and side effects. Depending on the approach, the benefits and side-effects are local and global, on land, at the coast, or in the open ocean. A good example are the impacts of large-scale mining efforts that would be necessary for alkalinity enhancement. Thus, perceptions along the entire process-chain of not just one approach but a portfolio of land- and ocean-based approaches will have to be disentangled.

\section{DATA AVAILABILITY STATEMENT}

The original contributions presented in the study are included in the article/supplementary material, further inquiries can be directed to the corresponding author/s.

\section{AUTHOR CONTRIBUTIONS}

$\mathrm{CM}$ had the initial idea and especially wrote the parts on climate engineering approaches. $\mathrm{CB}$ and $\mathrm{CM}$ contributed equally to developing the concept and writing the text. $\mathrm{CB}$ especially wrote the parts on coastal blue carbon approaches. All authors contributed to the article and approved the submitted version.

\section{FUNDING}

$\mathrm{CM}$ acknowledges funding from the European Union's Horizon 2020 research and innovation programme under grant agreement No 869357. CB acknowledges funding from Kiel Marine Science (KMS) - Centre for Interdisciplinary Marine Science at Kiel University (G1912 Economic assessments of coastal blue carbon ecosystems - ECOBLUE). CB further acknowledges funding for the research project SeaStore (Diversity Enhancement Through Seagrass Restoration) from the German Federal Ministry of Education and Research under grant agreement number 03F0859E. The publication of this article was funded by the Open Access Fund of the Leibniz Association. Estuar. Coast. Shelf Sci. 247:106751. doi: 10.1016/j.ecss.2020. 106751 
Badola, R., Barthwal, S., and Hussain, S. A. (2012). Attitudes of local communities towards conservation of mangrove forests: A case study from the east coast of India. Estuar. Coast. Shelf Sci. 96, 188-196. doi: 10.1016/j.ecss.2011.11.016

Bauer, D. M., Cyr, N. E., and Swallow, S. K. (2004). Public preferences for compensatory mitigation of salt marsh losses: a contingent choice of alternatives. Conserv. Biol. 18, 401-411. doi: 10.1111/j.1523-1739.2004.0 0367.x

Bellamy, R., and Osaka, S. (2020). Unnatural climate solutions? Nat. Clim. Change 10, 98-99. doi: 10.1038/s41558-019-0661-z

Bostrom, A., O'Connor, R. E., Böhm, G., Hanss, D., Bodi, O., Ekström, F., et al. (2012). Causal thinking and support for climate change policies: international survey findings. Glob. Environ. Change 22, 210-222. doi: 10.1016/j.gloenvcha.2011.09.012

Braun, C., Merk, C., Pönitzsch, G., Rehdanz, K., and Schmidt, U. (2018). Public perception of climate engineering and carbon capture and storage in Germany: survey evidence. Clim. Policy 18, 471-484. doi: 10.1080/14693062.2017.1304888

Carlisle, D. P., Feetham, P. M., Wright, M. J., and Teagle, D. A. H. (2020). The public remain uninformed and wary of climate engineering. Clim. Change 160, 303-322. doi: 10.1007/s10584-020-02706-5

Carr, W. A., and Yung, L. (2018). Perceptions of climate engineering in the South Pacific, Sub-Saharan Africa, and North American Arctic. Clim. Change 147, 119-132. doi: 10.1007/s10584-018-2138-x

Casagrande, D. G. (1997). Restoration of an Urban Salt Marsh: An Interdisciplinary Approach. Bulletin Series No. 100. New Haven, CT: Yale School of Forestry \& Environmental Studies.

Colvin, R. M., Kemp, L., Talberg, A., Castella, C., de, Downie, C., Friel, S., et al. (2020). Learning from the climate change debate to avoid polarisation on negative emissions. Environ. Commun. 14, 23-35. doi: 10.1080/17524032.2019.1630463

Corner, A., Parkhill, K., Pidgeon, N. F., and Vaughan, N. E. (2013). Messing with nature? Exploring public perceptions of geoengineering in the UK. Glob. Environ. Change 23, 938-947. doi: 10.1016/j.gloenvcha.2013.06.002

Corner, A., and Pidgeon, N. F. (2014). Like artificial trees? The effect of framing by natural analogy on public perceptions of geoengineering. Clim. Change 130, 425-438. doi: 10.1007/s10584-014-1148-6

Cox, E., Spence, E., and Pidgeon, N. (2020). Public perceptions of carbon dioxide removal in the United States and the United Kingdom. Nat. Clim. Change 10, 1-6. doi: 10.1038/s41558-020-0823-Z

Curado, G., Manzano-Arrondo, V., Figueroa, E., and Castillo, j. (2014). Public perceptions and uses of natural and restored salt marshes. Landsc. Res. 39, 668-679. doi: 10.1080/01426397.2013.772960

Demeritt, D. (2002). What is the 'social construction of nature'? A typology and sympathetic critique. Prog. Hum. Geogr. 26, 767-790. doi: 10.1191/0309132502ph402oa

Dütschke, E. (2011). What drives local public acceptance-comparing two cases from Germany: 10th international conference on greenhouse gas control technologies. Energy Proc. 4, 6234-6240. doi: 10.1016/j.egypro.2011.02.636

Figueiredo, M. A., de, Reiner, D. M., and Herzog, H. J. (2003). "Ocean carbon sequestration: a case study in public and institutional perceptions," in Greenhouse Gas Control Technologies - 6th International Conference, eds J. Gale and Y. Kaya (Oxford: Pergamon), 799-804.

Franke, A., Blenckner, T., Duarte, C. M., Ott, K., Fleming, L. E., Antia, A., et al. (2020). Operationalizing ocean health: toward integrated research on ocean health and recovery to achieve ocean sustainability. One Earth 2, 557-565. doi: 10.1016/j.oneear.2020.05.013

Fuss, S., Canadell, J. G., Peters, G. P., Tavoni, M., Andrew, R. M., Ciais, P., et al. (2014). Betting on negative emissions. Nat. Clim. Change 4, 850-853. doi: $10.1038 /$ nclimate2392

Gannon, K. E., and Hulme, M. (2018). Geoengineering at the "Edge of the World": exploring perceptions of ocean fertilisation through the Haida Salmon Restoration Corporation. Geogr. Environ. 5:e00054. doi: 10.1002/geo2.54

Gattuso, J.-P., Magnan, A. K., Bopp, L., Cheung, W. W. L., Duarte, C. M., Hinkel, J., et al. (2018). Ocean solutions to address climate change and its effects on marine ecosystems. Front. Mar. Sci. 5:337. doi: 10.3389/fmars.2018.00337

GESAMP (2019). High Level Review of a Wide Range of Proposed Marine Geoengineering Techniques: GESAMP Working Group 41. London: GESAMP.
Gewin, V. (2002). Ocean carbon study to quit Hawaii. Nature 417:888. doi: $10.1038 / 417888 b$

Giles, J. (2002). Norway sinks ocean carbon study. Nature 419:6. doi: 10.1038/419006b

Gough, C., Taylor, I., and Shackley, S. (2002). Burying carbon under the sea: an initial exploration of public opinions. Energy Environ. 13, 883-900. doi: 10.1260/095830502762231331

Grech, A., Chartrand-Miller, K., Erftemeijer, P., Fonseca, M., McKenzie, L., Rasheed, M., et al. (2012). A comparison of threats, vulnerabilities and management approaches in global seagrass bioregions. Environ. Res. Lett. 7:24006. doi: 10.1088/1748-9326/7/2/024006

Ha, T. T. T., van Dijk, H., and Bush, S. R. (2012). Mangrove conservation or shrimp farmer's livelihood? The devolution of forest management and benefit sharing in the Mekong Delta, Vietnam. Ocean Coast. Manag. 69, 185-193. doi: 10.1016/j.ocecoaman.2012.07.034

Hansen, A. (2006). Tampering with nature: 'nature' and the 'natural' in media coverage of genetics and biotechnology. Media Cult. Soc. 28, 811-834. doi: $10.1177 / 0163443706067026$

Hoegh-Guldberg, O., Chopin, T., Gaines, S., Haugan, P., Hemer, M., Howard, J., et al. (2019a). The Ocean as a Solution to Climate Change: Five Opportunities for Action. Washington, DC: World Resources Institute. Available online at: http:// www.oceanpanel.org/climate (accessed December 8, 2020).

Hoegh-Guldberg, O., Northrop, E., and Lubchenco, J. (2019b). The ocean is key to achieving climate and societal goals. Science 365, 1372-1374. doi: 10.1126/science.aaz4390

Hugé, J., Vande Velde, K., Benitez-Capistros, F., Japay, J. H., Satyanarayana, B., Nazrin Ishak, M., et al. (2016). Mapping discourses using Q methodology in Matang Mangrove Forest, Malaysia. J. Environ. Manag. 183, 988-997. doi: 10.1016/j.jenvman.2016.09.046

Ibrahim, I., Aminudin, N., Young, M. A., and Yahya, S. A. I. (2012). Education for wetlands: public perception in Malaysia. Proc. Soc. Behav. Sci. 42, 159-165. doi: $10.1016 /$ j.sbspro.2012.04.177

Ilyina, T., Wolf-Gladrow, D., Munhoven, G., and Heinze, C. (2013). Assessing the potential of calcium-based artificial ocean alkalinization to mitigate rising atmospheric $\mathrm{CO}_{2}$ and ocean acidification. Geophys. Res. Lett. 40, 5909-5914. doi: 10.1002/2013GL057981

IPCC (2018). "Summary for policymakers," in Global Warming of $1.5^{\circ} \mathrm{C}: \mathrm{An}$ IPCC Special Report on the Impacts of Global Warming of $1.5^{\circ} \mathrm{C}$ Above Preindustrial Levels and Related Global Greenhouse Gas Emission Pathways, in the Context of Strengthening the Global Response to the Threat of Climate Change, Sustainable Development, and Efforts to Eradicate Poverty, eds V. MassonDelmotte, P. Zhai, H. -O. Pörtner, D. Roberts, J. Skea, and P. R. Shukla. (Geneva: Intergovernmental Panel on Climate Change).

Ipsos MORI (2010). Experiment Earth? Report on a Public Dialogue on Geoengineering. Available online at: http://www.nerc.ac.uk/about/whatwedo/ engage/engagement/geoengineering/geoengineering-dialogue-final-report/ (accessed December 8, 2020).

Itaoka, K., Okuda, Y., Saito, A., and Akai, M. (2009). Influential information and factors for social acceptance of CCS: The 2nd round survey of public opinion in Japan: greenhouse gas control technologies 9 proceedings of the 9th international conference on greenhouse gas control technologies (GHGT9), 16-20 November 2008, Washington DC, USA. Energy Proc. 1, 4803-4810. doi: 10.1016/j.egypro.2009.02.307

Jefferson, R. L., Bailey, I., Laffoley, D., d., Richards, J. P., and Attrill, M. J. (2014). Public perceptions of the UK marine environment. Mar. Policy 43, 327-337. doi: 10.1016/j.marpol.2013.07.004

Jobin, M., and Siegrist, M. (2020). Support for the deployment of climate engineering: a comparison of ten different technologies. Risk Anal. 40, 1058-1078. doi: 10.1111/risa.13462

Keller, D. P., Feng, E. Y., and Oschlies, A. (2014). Potential climate engineering effectiveness and side effects during a high carbon dioxide-emission scenario. Nat. Commun. 5:3304. doi: 10.1038/ncomms4304

Keller, D. P., Lenton, A., Littleton, E. W., Oschlies, A., Scott, V., and Vaughan, N. E. (2018). The effects of carbon dioxide removal on the carbon cycle. Curr. Clim. Change Rep. 4, 250-265. doi: 10.1007/s40641-018-0104-3

Leiserowitz, A., Smith, N., and Marlon, J. (2010). Americans' Knowledge of Climate Change. New Haven, CT: Yale Project on Climate Change Communication. 
Retrieved from Q237. New technologies can solve global warming, without individuals having to make big changes in their lives.

Liski, A. H., Ambros, P., Metzger, M. J., Nicholas, K. A., Wilson, A. M. W., and Krause, T. (2019). Governance and stakeholder perspectives of managed re-alignment: Adapting to sea level rise in the Inner Forth estuary, Scotland. Reg. Environ. Change 19, 2231-2243. doi: 10.1007/s10113-019-0 1505-8

López-Medellín, X., Castillo, A., and Ezcurra, E. (2011). Contrasting perspectives on mangroves in arid Northwestern Mexico: implications for integrated coastal management. Ocean Coast. Manag. 54, 318-329. doi: 10.1016/j.ocecoaman.2010.12.012

L'Orange Seigo, S., Dohle, S., and Siegrist, M. (2014). Public perception of carbon capture and storage (CCS): a review. Renew. Sust. Energy Rev. 38, 848-863. doi: 10.1016/j.rser.2014.07.017

Lovelock, C. E., and Reef, R. (2020). Variable impacts of climate change on blue carbon. One Earth 3, 195-211. doi: 10.1016/j.oneear.2020.07.010

Macreadie, P. I., Anton, A., Raven, J. A., Beaumont, N., Connolly, R. M., Friess, D. A., et al. (2019). The future of blue carbon science. Nat. Commun. 10:3998. doi: 10.1038/s41467-019-11693-w

Merk, C., Klaus, G., Pohlers, J., Ernst, A., Ott, K., and Rehdanz, K. (2019). Public perceptions of climate engineering: Laypersons' acceptance at different levels of knowledge and intensities of deliberation. GAIA 28, 348-355. doi: 10.14512/gaia.28.4.6

Myatt, L. B., Scrimshaw, M. D., and Lester, J. N. (2003). Public perceptions and attitudes towards an established managed realignment scheme: Orplands, Essex, UK. J. Environ. Manag. 68, 173-181. doi: 10.1016/S0301-4797(03)00065-3

Nordlund, L. M., Jackson, E. L., Nakaoka, M., Samper-Villarreal, J., Beca-Carretero, P., and Creed, J. C. (2018). Seagrass ecosystem services - What's next? Mar. Pollut. Bull. 134, 145-151. doi: 10.1016/j.marpolbul.2017.09.014

Nordlund, L. M., La Torre-Castro, M., de, Erlandsson, J., Conand, C., Muthiga, N., Jiddawi, N., et al. (2014). Intertidal zone management in the Western Indian Ocean: assessing current status and future possibilities using expert opinions. Ambio 43, 1006-1019. doi: 10.1007/s13280-013-0465-8

Palmgren, C. R., Morgan, M. G., Bruine de Bruin, W., and Keith, D. W. (2004). Initial public perceptions of deep geological and oceanic disposal of carbon dioxide. Environ. Sci. Technol. 38, 6441-6450. doi: 10.1021/ es $040400 \mathrm{c}$

Paluszny, A., Graham, C. C., Daniels, K. A., Tsaparli, V., Xenias, D., Salimzadeh, S., et al. W. (2020). Caprock integrity and public perception studies of carbon storage in depleted hydrocarbon reservoirs. Int. J. Greenh. Gas Control 98:103057. doi: 10.1016/j.ijggc.2020.103057

Pidgeon, N. F., Parkhill, K., Corner, A., and Vaughan, N. E. (2013). Deliberating stratospheric aerosols for climate geoengineering and the SPICE project. Nat. Clim. Change 3, 451-457. doi: 10.1038/nclimate1807

Queiroz, L., d,. S., Rossi, S., Calvet-Mir, L., Ruiz-Mallén, I., García-Betorz, S., et al. (2017). Neglected ecosystem services: highlighting the socio-cultural perception of mangroves in decision-making processes. Ecosyst. Serv. 26, 137-145. doi: 10.1016/j.ecoser.2017.06.013

Rahman, M. A. A., and Asmawi, M. Z. (2016). Local residents' Awareness towards the issue of mangrove degradation in Kuala Selangor, Malaysia. Proc. Soc. Behav. Sci. 222, 659-667. doi: 10.1016/j.sbspro.2016.05.222

Rickels, W., Merk, C., Reith, F., Keller, D., and Oschlies, A. (2019). (Mis)conceptions about modelling of negative emissions technologies. Environ. Res. Lett. 14:104004. doi: 10.1088/1748-9326/ab3ab4

Rönnbäck, P., Crona, B., and Ingwall, L. (2007). The return of ecosystem goods and services in replanted mangrove forests: Perspectives from local communities in Kenya. Environ. Conserv. 34, 313-324. doi: 10.1017/S0376892907004225

Roy, A. K. D. (2016). Local community attitudes towards mangrove forest conservation: lessons from Bangladesh. Mar. Policy 74, 186-194. doi: 10.1016/j.marpol.2016.09.021

Royal Society (2009). Geoengineering the Climate: Science, Governance and Uncertainty: Royal Society. Available online at: http://eprints.soton.ac.uk/ 156647/1/Geoengineering_the_climate.pdf (accessed December 8, 2020).

Schiermeier, Q. (2009a). Ocean Fertilization Experiment Draws Fire: Indo-German Research Cruise Sets Sail Despite Criticism. Available online at: https://www. nature.com/news/2009/090109/full/news.2009.13.html (accessed December 8, 2020).
Schiermeier, Q. (2009b). Ocean Fertilization Experiment Suspended: German Science Ministry Demands Environmental Assessment Before Nutrient Dumping Can Begin. Available online at: https://www.nature.com/news/2009/090114/ full/news.2009.26.html (accessed December 8, 2020).

Schumann, D., Duetschke, E., and Pietzner, K. (2014). Public perception of $\mathrm{CO}_{2}$ offshore storage in germany: regional differences and determinants. Energy Proc. 63, 7096-7112. doi: 10.1016/j.egypro.2014.11.744

Scott, K. N. (2006). The day after tomorrow: ocean $\mathrm{CO}_{2}$ sequestration and the future of climate change. Georget. Int. Environ. Law Rev. 18, 57-108.

Shrum, T. R., Markowitz, E., Buck, H., Gregory, R., van der Linden, S., Attari, S. Z., et al. (2020). Behavioural frameworks to understand public perceptions of and risk response to carbon dioxide removal. Interface Focus 10:20200002. doi: 10.1098/rsfs.2020.0002

Smith, P., Adams, J., Beerling, D. J., Beringer, T., Calvin, K. V., Fuss, S., et al. (2019). Land-management options for greenhouse gas removal and their impacts on ecosystem services and the sustainable development goals. Annu. Rev. Environ. Resour. 44, 255-286. doi: 10.1146/annurev-environ-101718-033129

Srivastava, S., and Mehta, L. (2017). The Social Life of Mangroves: Resource Complexes and Contestations on the Industrial Coastline of Kutch, India (STEPS Working Paper No. 99). STEPS Centre: Brighton.

Stone, K., Bhat, M., Bhatta, R., and Mathews, A. (2008). Factors influencing community participation in mangroves restoration: a contingent valuation analysis. Ocean Coast. Manag. 51, 476-484. doi: 10.1016/j.ocecoaman.2008.02.001

Thomas, G., Pidgeon, N., and Roberts, E. (2018). Ambivalence, naturalness and normality in public perceptions of carbon capture and storage in biomass, fossil energy, and industrial applications in the United Kingdom. Energy Res. Soc. Sci. 46, 1-9. doi: 10.1016/j.erss.2018.06.007

Tollefson, J. (2017). Plankton-boosting project in Chile sparks controversy: Canadian foundation says its planned ocean-fertilization experiment could help fisheries. Nature 545, 393-394. doi: 10.1038/545393a

Tuan, T. H., My, N. H. D., Le Anh, T. Q., and van Toan, N. (2014). Using contingent valuation method to estimate the WTP for mangrove restoration under the context of climate change: a case study of Thi Nai lagoon, Quy Nhon city, Vietnam. Ocean Coast. Manag. 95, 198-212. doi: 10.1016/j.ocecoaman.2014.04.008

Upham, P., and Roberts, T. (2011). Public perceptions of CCS in context: results of NearCO2 focus groups in the UK, Belgium, the Netherlands, Germany, Spain and Poland: 10th International Conference on Greenhouse Gas Control Technologies. Energy Proc. 4, 6338-6344. doi: 10.1016/j.egypro.2011.02.650

Vande Velde, K., Hugé, J., Friess, D. A., Koedam, N., and DahdouhGuebas, F. (2019). Stakeholder discourses on urban mangrove conservation and management. Ocean Coast. Manag. 178:104810. doi: 10.1016/j.ocecoaman.2019.05.012

Wandersee, J. H., and Schussler, E. E. (2001). Toward a theory of plant blindness. Plant Sci. Bull. 47, 2-9. doi: 10.1111/cobi.12738

West, R. J. (2010). Rehabilitation of seagrass and mangrove sites-successes and failures in NSW. Wetlands Aust. 14, 13-19. doi: 10.31646/wa.173

Winickoff, D. E., Flegal, J. A., and Asrat, A. (2015). Engaging the global south on climate engineering research. Nat. Clim. Change 5, 627-634. doi: 10.1038/nclimate2632

Wolske, K. S., Raimi, K. T., Campbell-Arvai, V., and Hart, P. S. (2019). Public support for carbon dioxide removal strategies: the role of tampering with nature perceptions. Clim. Change 152, 345-361. doi: 10.1007/s10584-019-02375-z

Wright, M. J., Teagle, D. A. H., and Feetham, P. M. (2014). A quantitative evaluation of the public response to climate engineering. Nat. Clim. Change 4, 106-110. doi: 10.1038/nclimate2087

Conflict of Interest: The authors declare that the research was conducted in the absence of any commercial or financial relationships that could be construed as a potential conflict of interest.

Copyright () 2020 Bertram and Merk. This is an open-access article distributed under the terms of the Creative Commons Attribution License (CC BY). The use, distribution or reproduction in other forums is permitted, provided the original author(s) and the copyright owner(s) are credited and that the original publication in this journal is cited, in accordance with accepted academic practice. No use, distribution or reproduction is permitted which does not comply with these terms. 